\title{
Democracia, transparência e accountability: modelagem de avaliação de portais de transparência
}

A necessidade da transparência e elementos de accountability dos atos de governo vêm sendo altamente requerida pela sociedade que tem clamado por um país mais transparente, mais digno, mais democrático. Principalmente a partir da vigência da Constituição Federal de 1988, a administração pública vem adotando normativas e práticas de transparência para incentivar o controle social. A partir de revisão literária em trabalhos científicos, legislação e manifestações da sociedade civil, buscou-se nesta pesquisa criar uma modelagem de avaliação que incorporasse elementos de democracia, accountability e transparência. A modelagem foi denominada TLS por trazer a síntese de aspectos teóricos, legais e sociais em sua avaliação. A partir de oito modelos originais, chegou-se a um checklist com 109 itens avaliativos. A modelagem foi aplicada no portal transparência do Estado de Goiás e avaliou-se numa escala de cinco níveis, que o site possui o terceiro nível de transparência dentre os parametrizados. Após a compilação dos resultados da pesquisa, concluiu-se que, apesar de o portal apresentar características funcionais de boa qualidade, ampla gama de informações e serviços, ele não contribui com plenitude para o exercício do controle social pelo cidadão, pois não há espaços de interação, falta incentivo à participação social e algumas informações não são prestadas de forma tempestiva o que dificulta o diálogo entre Poder Público e sociedade.

Palavras-chave: Democracia; Accountability; Transparência; Modelagem TLS; Portal Goiás Transparente.

\section{Democracy, transparency and accountability: transparency portals assessment framework}

\begin{abstract}
The need for transparency and accountability elements in government acts have been highly requested by the population that has claimed for a country that is more transparent, more worth living, more democratic. The Brazilian public administration has been adopting regulatory practices, as well as, transparency measures, to encourage social control since the Constitution of 1988. This research aimed at devising, through thorough literature review of academic publishing in the area, an assessment framework which featured elements of democracy, accountability, and transparency. The model was called TLS, for it considers theoretical, legal and social aspects in its assessments. A checklist parting from eight original models was obtained, with 109 assessment items. The model was applied on the transparency portal of the Brazilian state of Goiás - and evaluated on a five-level scale, where the website has reached the third level of transparency. After compiling the research results, it was concluded that, although the portal has good quality functional characteristics, a wide range of information and services, it does not fully contribute to the exercise of social control by the citizen, because there are no spaces for interaction, lack of incentive for social participation and some information is not provided in a timely manner, which hinders the dialogue between government and society.
\end{abstract}

Keywords: Democracy; Accountability; Transparency; TLS Model; Goiás Transparent Portal.

Topic: Gestão Pública

Reviewed anonymously in the process of blind peer.
Received: 09/12/2019

Approved: 14/01/2020
Eliseu Vieira Machado Júnior (iD)

Universidade Federal de Goiás, Brasil

http://lattes.cnpq.br/8124167890774604

http://orcid.org/0000-0003-3829-2275

eliseumachadojr@hotmail.com

Claudia Regina Rosal Carvalho (id

Universidade Federal de Goiás, Brasil

http://lattes.cnpq.br/4883069832734425

http://orcid.org/0000-0003-0913-9562

clregina@hotmail.com
Referencing this:

MACHADO JÚNIOR, E. V.; CARVALHO, C. R. R.. Democracia, transparência e accountability: modelagem de avaliação de portais de transparência. Revista Brasileira de Administração Científica, v.11, n.1, p.127-144, 2020. DOI: http://doi.org/10.6008/CBPC2179684X.2020.001.0010

DOI: 10.6008/CBPC2179-684X.2020.001.0010 


\section{INTRODUÇÃO}

Os últimos anos no Brasil vem sendo marcados por constantes manifestações públicas individuais e coletivas que clamam pelo fim da corrupção nas diversas esferas de governo. Nesse contexto, conceitos como transparência pública e accountability - termo aqui aplicado no sentido da obrigação governamental de prestação de contas aos cidadãos - nunca foram tão imprescindíveis no jogo político. Entre os cidadãos despertou, não se discutindo a forma como ocorre, uma bidimensionalidade democrática: o direito da escolha de seus representantes e a fiscalização dos atos dos escolhidos na representatividade. Por parte da Administração Pública, há a preocupação recente e atual em se criar meios para que o cidadão tenha acesso transparente à informação e tenha plena oportunidade de exercer seu direito de controle social sobre os atos de seus governantes, possibilitando a accountability vertical proposta por O'Donnel (1991).

A governança brasileira recepcionou o dispositivo legal - Constituição Federal de 1988, Lei de Responsabilidade Fiscal (2000), Lei de Transparência (2009) e Lei de Acesso à Informação (2011) - dispondo de importantes ferramentas para o fortalecimento da transparência e da accountability. Contudo, somente o aspecto legal não é capaz de garanti-los e, por isso, a proposta é criar uma modelagem que perpasse os marcos legais e incorpore outros critérios. Dessa forma, a modelagem aproximar-se-á de um conjunto de informações de maior completude que possibilite ao cidadão o livre exercício do controle sobre os atos de seus governantes e uma participação no processo decisório de um maior número de pessoas e de qualidade argumentativa, remetendo ao exercício democrático proposto por Habermas (1997) e sua teoria deliberativa.

Diante disso, tem-se a seguinte pergunta de pesquisa: Quais os critérios desejáveis devem ser observados em portais eletrônicos de transparência brasileiros, de modo que incorporem elementos de transparência e accountability e permitam, por parte da Administração Pública, o exercício da democracia deliberativa?.

O objetivo da pesquisa é desenvolver um instrumento de avaliação que incorpore os elementos da Transparência, Accountability e possibilitadores de exercício da democracia participativa-deliberativa e aplicálo no portal eletrônico da transparência do Estado de Goiás. A escolha de dados pelo estado de Goiás foi feita, porque apesar de haver vários estudos sobre transparência pública e também várias tentativas de mensurála, são ínfimos os estudos científicos sobre o tema para o estado de Goiás.

Espera-se com esta pesquisa que se forneça um novo instrumento de avaliação de portais eletrônicos de transparência, que em primeiro lugar, oferecerá à sociedade uma ferramenta que auxilie na sua efetiva participação no controle dos atos de governo. Em segundo lugar, a modelagem poderá servir de fonte para que os portais eletrônicos de transparência se ajustem e ofereçam informações mais completas e úteis a seus públicos.

\section{METODOLOGIA}

\section{Concepções sobre a democracia}

A ideia de democracia surgiu na Grécia Antiga, em Atenas, e, segundo Lago (2008) os conceitos 
modernos foram moldados a partir das Revoluções Americana e Francesa, no fim do século XVIII, que findaram com as monarquias absolutistas vigentes nos continentes americano e europeu. Mas a síntese é a de que a democracia é uma das várias formas de governo na qual “o poder não está nas mãos de um só ou de poucos, mas de todos, ou melhor, da maior parte, como tal se contrapondo às formas autocráticas, como a monarquia e oligarquia" (BOBBIO, 2000).

Rousseau (1995) e Locke (1973) são defensores da ideia do pacto social, no qual os homens abrem mão de suas liberdades individuais em nome do bem comum e da vontade geral de um povo. Para Rousseau (1995) a soberania popular é um poder conferido pelo pacto social, que é um corpo político dirigido pela vontade geral. O pacto social pacificaria e solucionaria conflitos presentes no estado natural em que a força é limitadora de direitos. Para Locke (1973) foi necessário que surgisse um poder imparcial que gerisse os conflitos entre as pessoas, já que elas possuem direitos iguais, e para isso, elas abdicaram de vontades pessoais particulares e transferiram as decisões para o Estado, que representa a vontade da maioria.

Schumpeter (1984) critica a teoria democrática clássica ao afirmar, em primeiro lugar, que não há um bem comum, pois isso pode significar diversas coisas para cada indivíduo; em segundo lugar, que não há uma soberania popular, mas um governo aprovado pelo povo, pois o povo, em sua maioria, é incapaz de tomar decisões para toda uma nação, já que não detém conhecimentos técnicos diversificados e sua vontade é manipulada pela publicidade política. Para este autor, a democracia é um método (não uma finalidade em si) pelo qual o povo toma decisões e deve ser uma competição periódica entre as elites políticas pelo poder de decisão em busca de votos da população. Os vencedores formariam aí o governo aprovado pelo povo.

Habermas (1997) traz a concepção procedimental da teoria deliberativa, na qual a legitimidade do processo democrático deriva principalmente da participação dos cidadãos no processo democrático, que vai além do voto. A teoria harbemasiana admite dificuldades de participação dos cidadãos trazidas pelas propriedades espacial e temporal das instituições das sociedades complexas e por isso propõe alternativas pelas quais os cidadãos e seus representantes debatam as questões em fóruns públicos antes das decisões. Propõe um modelo de democracia baseada na teoria deliberativa, o qual deve ser analisado a partir da relação entre o sistema político administrativo e a sociedade.

Na história da recente democracia brasileira, Menezes et al. (2019) observam a articulação de diversos atores com o objetivo de ampliar a capacidade de influência da sociedade civil nas esferas estatais, reorganizando os arranjos institucionais já existentes ou inovando a partir de novos instrumentos. À jovem democracia brasileira concedeu-se a democracia direta, participativa e deliberativa e houve esforços do próprio governo para que ela se estabelecesse. Além das estruturas institucionais seriam necessários outros elementos. O exercício desse poder pelo povo requer conhecimento, já que como afirma Schumpeter (1984) o povo não possui capacidade técnica para opinar e não há o que se falar em opinião e vontade geral. Esse conhecimento também é requerido pela teoria de Habermas, que propõe discussões em esferas públicas a propósito das decisões políticas a serem tomadas.

O conhecimento somente pode ser detido pelo povo por meio do amplo acesso às informações governamentais claras, precisas, úteis e tempestivas. Daí advém à necessidade da adoção da transparência 
pública. É pela transparência que a Administração Pública fornecerá aos cidadãos objeto de análise que auxiliará o processo de controle de sua gestão, legitimando seus atos.

\section{Accountability: suas definições e a necessidade da transparência como requisito basilar}

Schedler (1999) afirma que a essência da política é o poder e como consequência disso surge a necessidade de controlá-lo e a grande questão que emerge a partir daí é como manter o exercício do poder sob controle social. O termo accountability expressa a preocupação atual na supervisão, checagem, acompanhamento, observação e restrição institucional do exercício do poder. Segundo ele, a accountability contém duas conotações básicas: answerability, a obrigação de autoridades públicas de informar e explicar o que estão fazendo e enforcement (coação, constrangimento), que é a capacidade de agências de fiscalização e controle imporem sanções aos detentores do poder que violarem o dever público. Esse conceito bidimensional ultrapassa a simples análise radical ou semântica do termo accountability e pode ser descrito conforme suas próprias palavras "o esforço para garantir que o exercício de poder seja um empreendimento guiado e regulamentado" (SCHEDLER, 1999).

Pinho et al. (2009), em busca de uma compreensão na língua portuguesa para o significado das palavras accountability e accontable, estudaram o significado da palavra em dicionários da língua originária e também em estudos que buscaram uma tradução adequada à realidade brasileira. Na pesquisa em dicionários, os autores constataram que a ideia do termo accountability pode ser sintetizada em uma responsabilização pessoal por atos praticados e a exigente prontidão para a prestação de contas desses atos, com a possibilidade de ônus para quem não a praticar. Já o termo accontable estaria próximo ao sujeito responsável pela accountability, aquele que deve prestar contas de suas responsabilidades a ele delegadas. Os autores concordam com Schedler quando afirmaram que o objetivo da accountability é controlar o poder e, portanto, conclui-se que as penalidades devem ser fortes para quem não a pratica, para que o controle também o seja, pois, "o controle da atividade estatal deve ser visto como um dos eixos que dão sustentação ao regime democrático" (PINHO et al., 2009).

Para Akutsu et al. (2002), accountability é um conceito que envolve duas partes: primeiramente ocorre delegação de responsabilidade de uma parte para outra com a finalidade de gerir os recursos; em contrapartida, há a obrigação do gestor em prestar contas de sua gestão, demonstrando a forma como utiliza os recursos a ele confiados. A accountability não emerge por si só, mas sim da relação entre o Estado e a sociedade, na qual o cidadão exerce um papel ativo de sujeito guardião de seus direitos. Dessa forma, observa-se que a accountability possui dois atores essenciais: a administração pública e o cidadão. Cada um tem papel definido nesse mecanismo democrático, pois o controle é exercido por uma parte sobre a outra. A administração deve apresentar condições de ser controlada, avaliada e monitorada e o cidadão deve exercer seu papel de monitor e fiscalizador.

Referindo-se à forma como ocorre a cobrança dos atos públicos, O'Donnel (1991) apresenta a ideia de accountability sob duas vertentes: uma horizontal e outra vertical. Por accountability vertical, o autor afirma que seriam as ações realizadas individualmente ou coletivamente que se referem aos ocupantes das 
instituições do Estado, sejam eles eleitos ou não. Os canais seriam as eleições, as manifestações livres de reivindicações sociais e a cobertura da mídia. Já a accountability horizontal realiza-se por meio de agências estatais que detêm o direito e o poder legal e que estão dispostas e são capacitadas para realizar ações de supervisão e sanções legais contra ações ou omissões de outras agências do Estado qualificadas como delituosas. Aqui os canais da accountability seriam os poderes Executivo, Legislativo e Judiciário, além das agências de supervisão, como os ombusdman e as instâncias responsáveis pela fiscalização das prestações de contas.

O sentido de accountability vertical que exprime a ideia de que é dever da Administração Pública oferecer ao cidadão condições para que este possa exercer o controle social do poder, é a acepção que se busca nesta pesquisa. Para que accountability vertical se materialize, práticas de transparência pública são essenciais já que fornecerão as condições propícias para que o cidadão desempenhe seu papel fiscalizador e de monitoramento. Interligando os conceitos de accountability e transparência, tem-se que a transparência é o meio pelo qual se pode gerar a accountability no setor público, pois a responsabilização somente pode existir com o conhecimento gerado por meio de informações claras sobre a utilização dos recursos utilizados e os resultados gerados decorrentes das políticas públicas adotadas (BIZERRA, 2011). A transparência pública entendida aqui é aquela que a define como o processo de publicação das informações que são de interesse do cidadão, o que tornam mais democráticas as relações entre a sociedade e o mundo da política (GAMA NETO, 2014). A transparência depende de 'quão visível' é a informação e também de 'quão bem' essa visibilidade conduz a inferências corretas.

As informações disponibilizadas proativamente (transparência ativa) são obtidas mediantes pedidos (transparência passiva) não são um fim em sim mesmas, mas um meio utilizado para que se conheça melhor o que se passa nas organizações. A transparência é fundamental para a accoutability, pois permite a consulta das informações da gestão do patrimônio público e o exercício do controle social.

Mesmo diante de várias ferramentas de transparência presentes na governança brasileira - a exemplo dos portais de transparência e no ordenamento jurídico nacional, como a Lei de Acesso à Informação - LAI, o país ainda enfrenta dificuldades para uma aplicação efetiva da accountability. Mesmo diante de transformações gerenciais vividas na administração pública há mais de vinte anos, a cultura democrática resiste. Isso é observado por Andrade et al. (2019), ao afirmar que a responsabilização dessa resistência advém dos costumes arraigados do período colonial; da tardia previsão nos dispositivos legais que somente foram regulamentados e colocados em prática uma década depois de sua existência; e pela ação depender de uma sociedade que geralmente busca a conduta idônea, mas nem sempre age em prol de sua realização. A seguir serão apresentados estudos dos seguintes autores e suas contribuições: Vilella (2003), Rothberb et al. (2013), Viana et al. (2012), Leite Filho et al. (2015).

\section{RESULTADOS E DISCUSSÃO}

Modelo de avaliação de transparência sob as dimensões conteúdo, usabilidade e funcionalidade 
Vilella (2003), após revisar literatura sobre Governo Eletrônico, analisou cinco portais estaduais brasileiros sob três dimensões: conteúdo, usabilidade e funcionalidade. A autora criou um modelo de avaliação a partir da literatura existente e da opinião de especialistas nas dimensões de análise que foram propostas. Cada uma dessas dimensões compôs-se por parâmetros de análise e seus respectivos critérios de avaliação, conforme se vê no Quadro 1.

Quadro 1: Dimensões e parâmetros avaliativos

\begin{tabular}{|l|l|}
\hline Dimensão & Parâmetros \\
\hline Análise de Conteúdo & Abrangência, propósito e cobertura \\
& Atualidade \\
& Metadados \\
& Correção \\
& Autoridade/Copyright \\
& Objetividade \\
\hline Usabilidade & Inteligibilidade \\
& Apreensibilidade \\
& Operacionalidade \\
\hline Funcionalidade & Adequação \\
& Acurácia \\
& Interoperabilidade \\
& Conformidade \\
& Segurança de Acesso \\
\hline
\end{tabular}

Fonte: Adaptado de Vilella (2003)

A análise buscou a apuração técnica à luz da Ciência da Informação para avaliar portais de governos eletrônicos. Vilella (2003) primou pela qualidade do uso da tecnologia de sistemas para produzir um portal útil ao usuário, que possibilite o acesso facilitado e promova comunicação entre governo e sociedade.

\section{Modelo de avaliação das informações disponíveis sobre políticas públicas}

Rothberb et al. (2013) pesquisaram sobre a potencial contribuição dos portais eletrônicos de cidadessede das 15 regiões administrativas do Estado de São Paulo, quanto à afirmação da cidadania, na dimensão do exercício do direito à informação sobre políticas públicas. Os autores avaliaram a comunicação pública digital como fonte de informação sobre gestão pública, cuja metodologia de pesquisa consistiu em analisar o conteúdo por meio de planilhas eletrônicas que registraram a presença de informação correspondente a doze critérios de avaliação, conforme se vê no Quadro 2.

Quadro 2: Critérios observados na análise sobre políticas públicas.

\begin{tabular}{|l|l|l|}
\hline Critérios de avaliação & Recursos e ações atuais & Impacto (efetividade) \\
\hline Antecedentes & Recursos e ações planejadas & Custo efetividade \\
\hline Diagnósticos & Eficiência & Satisfação do usuário \\
\hline Objetivos & Eficácia & Equidade \\
\hline Metas &
\end{tabular}

Fonte: Adaptado de Rothberb et al. (2013).

Os autores afirmam que a segmentação de informações segundo estes critérios e sua disponibilidade online adequada pode contribuir para o provimento de avanços democráticos e é perceptível a preocupação dessa análise quanto ao aspecto comunicacional no que tange a completude e clareza das informações que podem auxiliar no processo de controle social dos atos de governo. 
Modelo de avaliação de transparência baseado em critérios internacionais

Viana et al. (2012) avaliaram a aderência aos critérios internacionais de transparência para a divulgação e apresentação das contas públicas do Portal de Transparência da Prefeitura Municipal de Manaus, por meio de um checklist avaliativo de 35 itens. A análise objetivou avaliar o estado da transparência eletrônica das contas da Prefeitura, em relação ao checklist e o grau de accountability possível a partir da avaliação. As fontes que originaram a lista avaliativa dos autores foram as seguintes: Organization for Economic Co-Operation and Development, International Budget Partnership, International Monetary Fund, Government Finance Officers Association, Halonen, Schellong et al. e Open Government Data. Os itens que compõem esse checklist estão observados no Quadro 3.

Quadro 3: Critérios internacionais de transparência.

\begin{tabular}{|l|l|l|}
\hline CRITÉRIOS & Ferramentas relevantes e flexíveis & Prioridades e problemas \\
\hline Acessibilidade & Históricos e bibliotecas & Processamento automático \\
\hline Atualização e Tempestividade & $\begin{array}{l}\text { Indicadores de desempenho não } \\
\text { financeiro }\end{array}$ & $\begin{array}{l}\text { Programas e ações de despesas e } \\
\text { receitas }\end{array}$ \\
\hline Classificações & $\begin{array}{l}\text { Informações de contratos, convênios e } \\
\text { outras formas de aplicação e origem de } \\
\text { recursos }\end{array}$ & Proposta orçamentária do executivo \\
\hline Comparações & Inteligibilidade & Relatório de auditoria \\
\hline Conversões & Links & Relatório de controle interno \\
\hline Dronogramas & Objetivos & Relatório final \\
\hline Dados e informações livres & Orçamento cidadão & Relatórios durante o exercício \\
\hline $\begin{array}{l}\text { Discussão dos patrimônios ativos e } \\
\text { obrigações empregatícias }\end{array}$ & Orçamento sintético & Relatório pré-eleitoral \\
\hline Dívidas e passivos & Orçamento promulgado & Relatório pré-orçamentário \\
\hline Fatores de influência em curto prazo & Outras ferramentas de usabilidade & Relatório semestral \\
\hline & Perspectivas de longo prazo & Sumário geral \\
\hline
\end{tabular}

Fonte: Viana et al. (2012).

Os autores optaram por esse modelo de checklist, pois a adoção de requisitos internacionais pode auxiliar para se chegar num modelo que favoreça uma accountability eficiente e transparência pública via internet com oferta da possibilidade de decisões aos usuários.

\section{Modelo de análise de transparência baseado no conteúdo e disclosure das informações sobre receita e} despesa pública

Leite Filho et al. (2015) indagaram sobre o nível de transparência dos seis municípios mais populosos do Estado de Minas Gerais. Para isso, verificaram se os municípios estavam cumprindo a Lei de Responsabilidade Fiscal (LC 101/2000) no que tange à disponibilização de informações, em tempo real, sobre a execução orçamentária e financeira de cada município.

Com base nas prerrogativas da Lei da Transparência (LC 131/09), analisaram a acessibilidade, disponibilidade e tempestividade das informações disponíveis nos meios eletrônicos de acesso público, sobre a programação e execução orçamentária e financeira de receitas e despesas públicas e outros documentos. Os critérios utilizados foram baseados na Lei da Transparência, compreendendo as seguintes dimensões dispostas no Quadro 4. 
Quadro 4: Análise de Conteúdo baseado no modelo do INESC.

\begin{tabular}{|l|l|}
\hline \multirow{5}{*}{ DIMENSÃO CONTEÚDO } & QUESITOS AVALIATIVOS \\
\cline { 2 - 3 } & Elaboração do orçamento \\
\cline { 2 - 3 } & Acesso à legislação orçamentária \\
\cline { 2 - 2 } & Conteúdo da legislação orçamentária \\
\cline { 2 - 2 } & Execução orçamentária \\
\cline { 2 - 2 } & Execução orçamentária do legislativo \\
\cline { 2 - 2 } & Avaliação \\
\hline
\end{tabular}

Fonte: Adaptado de Leite Filho et al. (2015).

Para fazer a avaliação da disclosure, definida por Leite Filho, Colares e Andrade (2015, p.124) como a “disseminação de informação relevante e confiável acerca do desempenho operacional, financeiro de uma entidade" foram utilizados os modelos INESC (2012) e um proposto por Nossa (2002), para o qual o conceito de disclosure liga-se aos objetivos da Contabilidade, fornecendo informações diferenciadas, tempestivas e transparentes a vários tipos de usuários da informação disponibilizada.

\section{Legislação brasileira e os instrumentos democráticos, possibilidades de accountability e transparência}

A Constituição Brasileira de 1988 legislou sobre o regime democrático resgatado no país e estabeleceu uma democracia híbrida que combina representação e participação direta, mas que também abre portas para a deliberação, regulamentada em outras leis. Com a finalidade de fortalecer o controle social intimamente ligado aos aspectos da accountability e transparência em nosso país, foram criadas a Lei Complementar 101/00 ou Lei de Responsabilidade Fiscal- LRF, a Lei Complementar 131/09 ou Lei da Transparência, o Decreto 7.185/10 e a Lei 12.527/11 ou Lei de Acesso à Informação - LAI.

Apontam Nunes et al. (2013) que algumas informações fornecidas eram restringidas aos órgãos públicos e, em especial, aos órgãos de controle externo, o que dificultava o alcance da sociedade às informações, dificultando o controle social. Com o advento da Lei da Transparência em 2009, isso foi corrigido. Os autores apontam que a LC 131/09 incluiu alguns dispositivos na Lei de Responsabilidade Fiscal que esclareceram quais informações devem ser divulgadas quanto à execução orçamentária e financeira. Tal normativa inovou por determinar a disponibilização em tempo real, de informações sobre a execução orçamentária e financeira da União, dos Estados, do Distrito Federal e dos Municípios e exigiu que os entes divulgassem na internet os seguintes dados exibidos no Quadro 5 a seguir:

Quadro 5: Dimensão, quesito e critério exigidos pela Lei da Transparência.

\begin{tabular}{|l|l|l|}
\hline \multicolumn{1}{|c|}{ Dimensão } & Quesito & \multicolumn{1}{c|}{ Critério } \\
\hline $\begin{array}{l}\text { Orçamento } \\
\text { público }\end{array}$ & Despesa & $\begin{array}{l}\text { Disponibilizar todos os atos no decorrer da execução da despesa, no momento de sua realização, } \\
\text { com a disponibilização mínima dos dados referentes ao número do correspondente processo, ao } \\
\text { bem fornecido ou ao serviço prestado, à pessoa física ou jurídica beneficiária do pagamento e, } \\
\text { quando for o caso, ao procedimento licitatório realizado }\end{array}$ \\
\hline & Receita & Disponibilizar o lançamento e o recebimento de toda a receita das unidades gestoras. \\
\hline
\end{tabular}

Fonte: Adaptado de Brasil (2009).

No ano de 2010, veio um novo avanço com o Decreto № 7.185 que regulamentou a Lei 131/09 e dispôs sobre o padrão mínimo de qualidade do sistema integrado de administração financeira e controle, no âmbito de cada ente da Federação. O mesmo decreto discriminou os elementos a serem divulgados quanto à despesa e receita, como pode ser visto no Quadro 6. 
Quadro 6: Elementos a serem divulgados pelo Sistema Integrado de Administração Financeira e Controle.

\begin{tabular}{|l|l|}
\hline \multicolumn{2}{|l|}{ Elementos a serem divulgados pelo Sistema Integrado de Administração Financeira e Controle } \\
\hline Receita & $\begin{array}{l}\text { - Previsão; } \\
\text { - Lançamento, se for o caso; e, } \\
\text { - Arrecadação }\end{array}$ \\
\hline & $\begin{array}{l}\text { - Valor do empenho, liquidação e pagamento; } \\
\text { - Número do correspondente processo da execução, quando for o caso; }\end{array}$ \\
Quanto à & $\begin{array}{l}\text { - A classificação orçamentária, especificando a unidade orçamentária, função, subfunção, natureza da despesa e } \\
\text { a fonte dos recursos que financiaram o gasto; }\end{array}$ \\
& $\begin{array}{l}\text { - A pessoa física ou jurídica beneficiária do pagamento, inclusive nos desembolsos de operações independentes } \\
\text { da execução orçamentária, exceto no caso de folha de pagamento de pessoal e de benefícios previdenciários; }\end{array}$ \\
& $\begin{array}{l}\text { - Procedimento licitatório realizado, bem como à sua dispensa ou inexigibilidade, quando for o caso, com o } \\
\text { número do correspondente processo; }\end{array}$ \\
& - e o bem fornecido ou serviço prestado, quando for o caso.
\end{tabular}

Fonte: Adaptado de Brasil (2010).

Os usuários da informação no Brasil ganharam outra ferramenta de transparência e accountability em novembro de 2011. Com o advento da Lei 12.527, conhecida como Lei de Acesso à Informação - LAl, foi regulamento o direito ao acesso às informações públicas, previsto na Constituição Federal. Essa lei representa uma mudança de paradigma na transparência pública, pois define como regra o acesso e como exceção, o sigilo. Qualquer pessoa, sem explicar a motivação, pode solicitar acesso a informações públicas (não sigilosas). Os princípios que orientam a LAI são os seguintes: princípio de publicidade máxima; princípio da transparência ativa e a obrigação de publicar; princípio da abertura de dados; princípio da promoção de um governo aberto; e princípio da criação de procedimentos que facilitem o acesso (CGU, 2013).

A LAI determina que a internet é o canal obrigatório de divulgação da transparência ativa (realizada espontaneamente pela administração) e para isso devem ser criadas páginas ou sites de acesso especialmente criados com essa finalidade ou no Portal de Transparência do estado/município. No Quadro 7, está disposto o rol mínimo de informações exigido pela LAI para órgãos e entidades públicas.

Quadro 7: Rol mínimo de informações exigido pela LAI.

\begin{tabular}{|l|l|}
\hline \multicolumn{1}{|c|}{ Dimensão } & \multicolumn{1}{c|}{ Quesito } \\
\hline \multirow{4}{*}{ Conteúdo mínimo relacionado à Transparência Ativa } & Institucional \\
\cline { 2 - 2 } & Receitas e Despesas \\
\cline { 2 - 2 } & Licitações e Contratos \\
\cline { 2 - 2 } & Ações e Programas \\
\cline { 2 - 2 } & Perguntas Frequentes \\
\hline \multirow{4}{*}{ Ferramentas, e suportes de navegação } & Pesquisa \\
\cline { 2 - 2 } & Ferramenta de pesquisa \\
\cline { 2 - 2 } & Relatórios digitais \\
\cline { 2 - 2 } & Divulgação da estruturação da informação \\
\cline { 2 - 2 } & Acessibilidade \\
\cline { 2 - 2 } & Comunicação \\
\hline
\end{tabular}

Fonte: Adaptado de CGU (2011) e CGU (2013).

Com o intuito de mensurar a qualidade da transparência nos estados e municípios brasileiros, a Controladoria Geral da União criou em 2015, a Escala Brasil Transparente (EBT). Seu objetivo, disposto em sua página da internet (CGU 2015) é avaliar o grau de cumprimento de dispositivos da Lei de Acesso à Informação (LAI) e a mensuração da efetividade da transparência passiva (Quadro 8).

Os instrumentos normativos brasileiros, a partir de 1988, foram se aperfeiçoando no tocante ao aspecto da transparência brasileira. Essas normativas caminharam para exigir dos entes federativos maior publicidade, detalhamento, tempestividade e completude às informações, com o foco final do cidadão, 
usuário da informação.

Quadro 8: Quesitos de avaliação da EBT.

\begin{tabular}{|l|l|}
\hline \multicolumn{1}{|c|}{ Dimensão } & \multicolumn{1}{c|}{ Quesito } \\
\hline Legislação e regulamentação & Regulamentação da Lei de Acesso à Informação \\
\hline Transparência passiva & Funcionamento do SIC \\
\hline
\end{tabular}

\section{A sociedade civil e o controle social sobre as práticas de transparência pública}

Disponibilizados os instrumentos de transparência pelo Estado, coube ao cidadão exercer o monitoramento do serviço prestado pelos entes federativos. Não foram encontrados destaques individuais na fiscalização dos recursos públicos brasileiros, mas sob a ótica da sociedade civil, a Associação Contas Abertas, organização social brasileira, por meio do Projeto Índice de Transparência - IT, propôs-se a avaliar o nível de transparência dos portais de informações públicas dos governos federal, estaduais e municipais do Brasil. Desde 2014, a metodologia adotada pelo IT, considera transparentes os governos que apresentam determinadas características quanto ao Conteúdo, Série Histórica e Frequência de utilização e Usabilidade.). No Quadro 9 estão especificados os quesitos a serem observados na avaliação do IT.

Quadro 9: Características determinantes para a transparência nos governos.

\begin{tabular}{|l|l|l|}
\hline \multicolumn{2}{|c|}{ Dimensão } & \multicolumn{2}{c|}{ Quesito } \\
\hline \multirow{4}{*}{ Conteúdo } & Etapas da execução orçamentária & Procedimento licitatório \\
\cline { 2 - 3 } & Classificação orçamentária & Convênios \\
\cline { 2 - 3 } & Nota de empenho & Receita \\
\cline { 2 - 3 } & Ordem bancária & Leis e Relatórios Orçamentários \\
\cline { 2 - 3 } & Beneficiário do pagamento & Patrimônio \\
\cline { 2 - 3 } $\begin{array}{l}\text { Série Histórica e Frequência de } \\
\text { Atualização }\end{array}$ & Informações agregadas & Outros Poderes \\
\hline \multirow{5}{*}{ Usabilidade } & Série histórica & Atualização \\
\hline & Interação & Visualização do conteúdo \\
\cline { 2 - 3 } & Possibilidade de download & formulário de consulta \\
\cline { 2 - 3 } & Formato de download & Gráficos \\
\cline { 2 - 3 } & Delimitação temporal das consultas & Acesso conforme modelo \\
\cline { 2 - 3 } & Disposição do conteúdo & \\
\hline
\end{tabular}

O IT possui metodologia desenvolvida por cientistas políticos, especialistas em gestão pública, economistas e outros pesquisadores brasileiros, sendo um trabalho reconhecido no país. É também utilizado de forma recorrente entre os meios de comunicação de massa brasileiros e tem sido inspiração metodológica em vários estudos científicos, entre eles Zuccoloto (2014), Pisa (2014), e Hosser (2015).

Seguindo os ensinamentos de Gil (1999), classifica-se esta pesquisa quanto à natureza como aplicada e quanto à abordagem como pesquisa qualitativa. Quanto aos objetivos, pode ser classificada como pesquisa descritiva, já que haverá descrição da situação do objeto estudado em detalhes. Quanto aos procedimentos técnicos, a pesquisa pode ser considerada dos seguintes tipos: bibliográfica, que definiu os critérios a serem adotados para a formulação de um modelo; documental, em razão da análise de dados disponíveis no portal eletrônico; estudo de caso, devido ao estudo detalhado de uma situação específica e ainda, pesquisa ação, por apresentar uma proposta que anseia por resolver problemas diagnosticados previamente.

Dentre os procedimentos técnicos apontados, merece destaque o estudo de caso nos moldes proposto por Yin (2001) que foi a estratégia utilizada para a investigação do objeto da pesquisa. Yin (2001) 
ensina que o estudo de caso investiga de forma empírica um fenômeno contemporâneo, considerando o ambiente contextual no qual este se desenvolve. É utilizado para se compreender um fenômeno social e complexo e como estratégia de pesquisa é um método abrangente que incorpora abordagens específicas à coleta de dados e à análise de dados. Machado Júnior (2009) reforça a importância do estudo de caso ao afirmar que tal método permite ao pesquisador observar o fenômeno em profundidade e que a opção pela pesquisa qualitativa é preferível quando se almeja construir teoria. Quanto ao caminho metodológico realizado na pesquisa, pode-se observá-lo na Figura 1 a seguir, que demonstra graficamente as quatro etapas presentes nesta investigação.

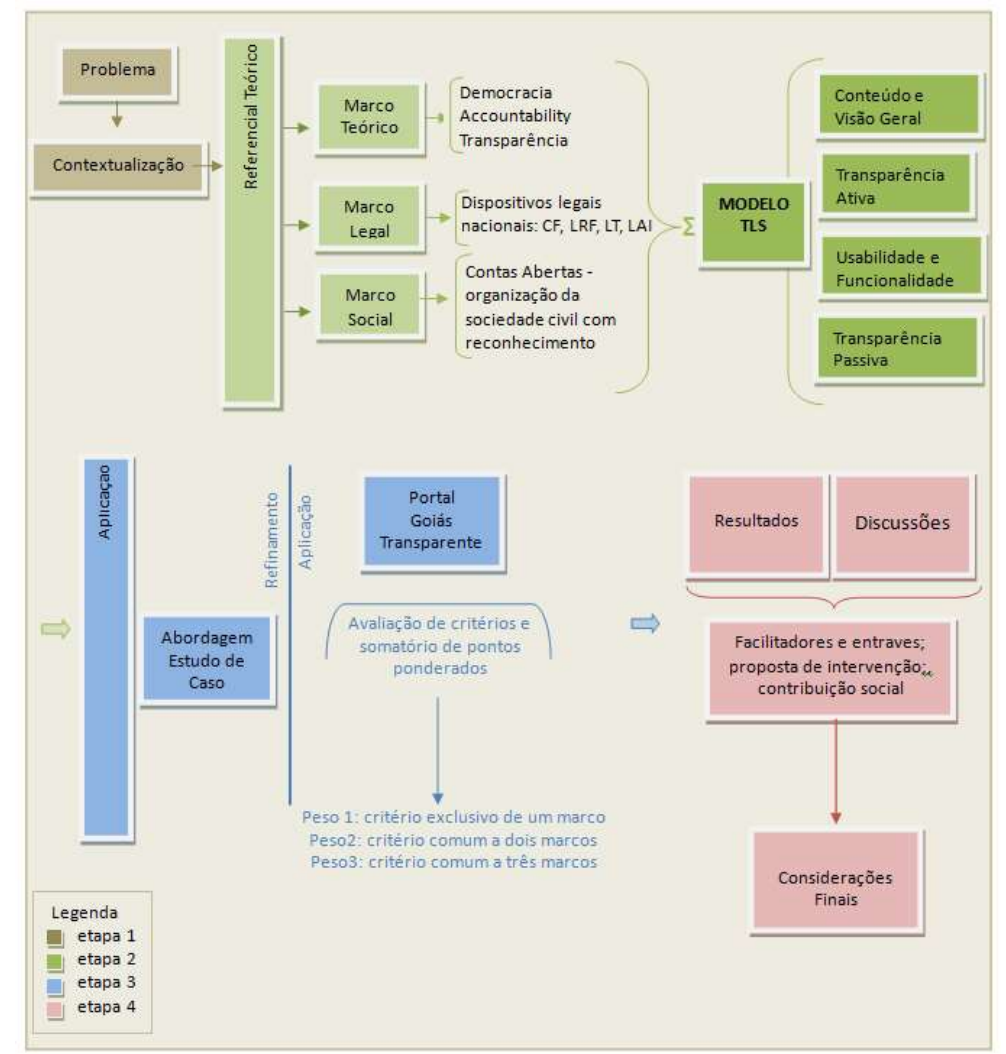

Figura 1: Caminho metodológico da pesquisa.

A Etapa 1 - Definição do problema de pesquisa, caracteriza-se pela motivação da investigação, revelada na identificação do problema e na sua contextualização. A Etapa 2 - Referencial Teórico, trouxe à discussão pontos relevantes sobre os conceitos de democracia, accountability e transparência; sobre a da legislação brasileira e sobre as formas de controle social no Brasil. Após a revisão literária, foi criada uma modelagem de mensuração da transparência, conforme ilustra a Figura 2.

Uma primeira síntese propôs condensar os critérios semelhantes ou iguais e somar os critérios complementares em cada dimensão, a fim de que se chegasse a três modelos. Novamente os três modelos foram sintetizados de modo que formassem a modelagem final, chamada de TLS (Teórico, Legal e Social). Após a síntese propôs-se uma divisão dos critérios em dimensões, baseada na informação que o critério fornece, conforme o Quadro 10. 


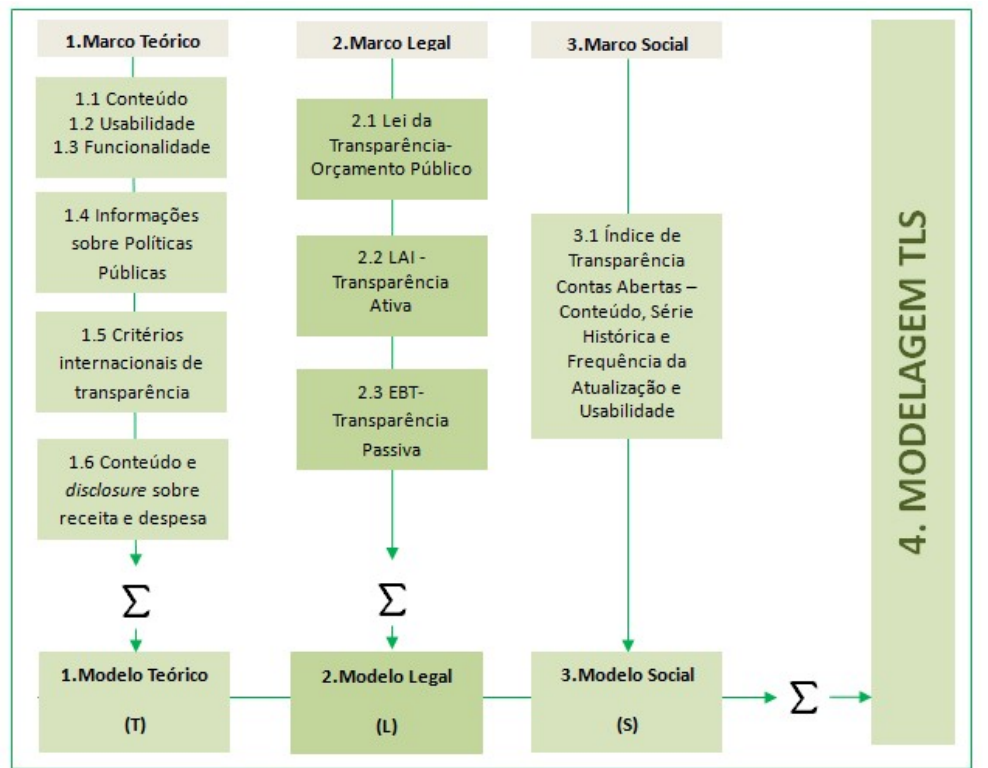

Figura 2: Metodologia da modelagem de avaliação TLS.

Quadro 10: Questões categorizadas em dimensões.

\begin{tabular}{|l|l|}
\hline Dimensão & Informação \\
\hline $\begin{array}{l}\text { Conteúdo e Visão } \\
\text { Geral }\end{array}$ & $\begin{array}{l}\text { Trata da identidade do site. Exposição das características, objetivos, metas, conteúdo, alinhamento com } \\
\text { política de governo e outras características que esclareçam o usuário sobre o uso e utilidade do site. }\end{array}$ \\
\hline Transparência Ativa & $\begin{array}{l}\text { Divulgação de dados por iniciativa do próprio setor público. Subdividida em Despesa, Receita, Patrimônio } \\
\text { e Prestação de Contas. }\end{array}$ \\
\hline $\begin{array}{l}\text { Usabilidade } \\
\text { Funcionalidade }\end{array}$ & $\begin{array}{l}\text { Verificação do planejamento gráfico, os serviços de navegação, comunicação, participação, privacidade, } \\
\text { links e outras questões sobre acessibilidade e operacionalidade do site. }\end{array}$ \\
\hline $\begin{array}{l}\text { Transparência } \\
\text { Passiva }\end{array}$ & $\begin{array}{l}\text { Divulgação de informações públicas em atendimento a demandas específicas de uma pessoa física ou } \\
\text { jurídica. }\end{array}$ \\
\hline
\end{tabular}

c) Etapa 3 - Aplicação, nesta etapa antes que as verificações dos critérios e quesitos fossem aplicadas no Portal Goiás Transparente, houve um refinamento na modelagem TLS. Tal medida foi necessária porque, algumas perguntas que compõem essa avaliação não se adequaram ao caso concreto do Portal de Transparência Eletrônica do Estado de Goiás e por isso foram descartadas.

Após o refinamento da Modelagem TLS foram aplicados os critérios de avaliação no portal Goiás Transparente. Os critérios receberam três possibilidades de respostas, sendo as seguintes: Atende, Não Atende, Atende Parcialmente. Para que os critérios fossem atendidos, seria necessário que os requisitos contidos na pergunta fossem cumpridos na íntegra pelo portal Goiás Transparente, observando-se o conteúdo quando à completude (informações completas) e tempestividade (atualizadas oportunamente). Para os critérios avaliados como não atendidos, notou-se a ausência de informações requeridas ou ainda a presença de conteúdo desatualizado, não tempestivo. Por fim, para que os critérios fossem avaliados como atendidos parcialmente, haveria a necessidade de que o portal contivesse a informação requerida, mesmo que de forma incompleta.

Como os critérios da modelagem TLS são a síntese de outros modelos, foi necessário fazer uma ponderação para o somatório de pontos baseada na formação do novo critério a partir dos critérios originais. Se o critério final se baseou em apenas um critério ou em critérios de mesmo marco - teórico, legal ou social, esse foi considerado como um critério frágil e por isso foi-lhe atribuído o Peso 1. Se o critério final foi formulado a partir de dois critérios e de diferentes marcos, foi considerado moderado e recebeu Peso 2. Mas, 
se caso o critério final foi formado a partir de três critérios dos três marcos, foi considerado como forte e recebeu Peso 3.

d) Etapa 4 - Resultados, discussões e propostas de intervenção: após aplicação da modelagem TLS, aqui foi obtido o aproveitamento percentual (69,37\%) pelo Portal Goiás Transparente. Diante disso, passouse à classificação do portal, alocando-o em faixas de aferição.

Para realizar o enquadramento da avaliação do Portal Goiás Transparente nas faixas de aferição, adotou-se aqui o mesmo escalonamento utilizado pelo índice IDHM (Índice de Desenvolvimento Humano Municipal), uma versão do IDH (Índice de Desenvolvimento Humano) desenvolvido pelo PNUD (Programa das Nações Unidas para o Desenvolvimento). O IDHM é uma medida composta pelo resultado de indicadores de três dimensões do desenvolvimento humano (longevidade, educação e renda). Faz-se uma média geométrica resultante do desempenho de cada dimensão e chega-se ao índice, que varia de 0 a 1 , sendo que, quanto mais próximo de 1, maior o desenvolvimento humano (PNUD, 2016). A adoção de tal índice justifica-se, pois se trata de ferramenta já reconhecida, testada e utilizada em nível mundial, como apontou Pisa (2014), a qual também utilizou da mesma inspiração para avaliar a governança pública a partir de um índice por ela criado. A Figura 3 apresenta as escalas e as faixas de aferição inspiradas na escala IDHM para os resultados obtidos a partir da aplicação da modelagem TLS.

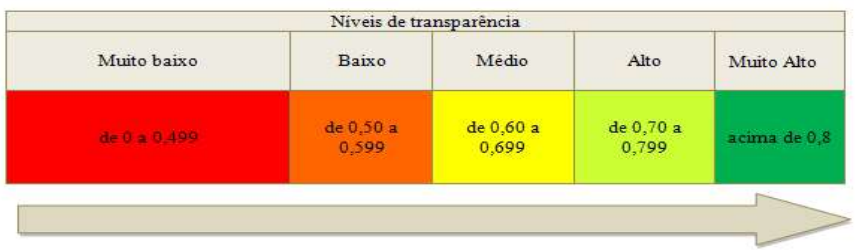

Figura 3: Escala das faixas de resultado da modelagem TLS. Fonte: Pisa (2014) e PNUD (2016).

O checklist avaliativo da Modelagem TLS foi aplicado no portal Goiás Transparente entre os dias 15 de março de 2019 a 20 de abril de 2019. Após avaliação de cada item do checklist da Modelagem TLS, o portal Goiás Transparente obteve no geral, 68,66\% de aproveitamento no atendimento aos 109 itens avaliativos, perfazendo a pontuação de 97,5 pontos dentre os possíveis 142 pontos. A dimensão mais bem pontuada foi Transparência Passiva, que atingiu $80 \%$ de aproveitamento, seguida pela dimensão Usabilidade e Funcionalidade, com 78,41\% de aproveitamento, conforme se vê no Quadro 11.

Quadro 11: Atendimento aos critérios avaliativos da modelagem TLS pelo portal Goiás Transparente.

\begin{tabular}{|l|l|l|l|}
\hline DIMENSÃO & ATENDIMENTO AOS CRITÉRIOS & VALOR MÁXIMO & \% DO VALOR MÁXIMO \\
\hline 1. Conteúdo e Visão Geral & 22 & 35 & 62,85 \\
\hline 2. Transparência Ativa & 36 & 57 & 63,15 \\
\hline 3. Usabilidade e funcionalidade & 34,5 & 44 & 78,41 \\
\hline 4. Transparência Passiva & 4 & 5 & $80 \%$ \\
\hline
\end{tabular}

A pontuação das dimensões variou entre 62,85\% (Dimensão Conteúdo e Visão Geral) e $84 \%$ (Dimensão Transparência Passiva) de aproveitamento. Dentro desses parâmetros, o portal Goiás Transparente, sob a avaliação da Modelagem TLS de Transparência, foi classificado com médio nível de Transparência. 
Quadro 12: Entraves percebidos no portal Goiás Transparente sob avaliação da modelagem TLS.

\begin{tabular}{|c|c|}
\hline \multicolumn{2}{|l|}{ Dimensão Conteúdo e Visão Geral } \\
\hline Entraves & Propostas de intervenção \\
\hline $\begin{array}{l}\text { - Faltam informações sobre a responsabilização do } \\
\text { servidor em caso de descumprimento a LAI } \\
\text { - Falta a regulamentação do SIC } \\
\text { - Faltam informações da CGE, órgão ao qual se vincula o } \\
\text { portal } \\
\text { - O escopo do portal não está devidamente detalhado } \\
\text { - Falta definição do público-alvo } \\
\text { - O portal não está disponível em outros idiomas } \\
\text { - Falta alinhamento entre o propósito do portal e o } \\
\text { conteúdo da homepage } \\
\text { - Acompanhamento de programas e ações refere-se ao } \\
\text { PPA não vigente } \\
\text { - Erros de grafia }\end{array}$ & $\begin{array}{l}\text { - Disponibilizar informações sobre a responsabilização do servidor } \\
\text { em caso de descumprimento da LAI. } \\
\text { - Disponibilizar a regulamentação do SIC } \\
\text { - Disponibilizar informações da CGE } \\
\text { - Detalhar o escopo do portal } \\
\text { - Definir o público-alvo do portal } \\
\text { - Disponibilizar consulta do portal em outros idiomas } \\
\text { - Fazer alinhamento entre o propósito do portal e o conteúdo da } \\
\text { homepage } \\
\text { - Disponibilizar programas e ações referentes ao PPA vigente } \\
\text { - Corrigir erros de grafia encontrados }\end{array}$ \\
\hline \multicolumn{2}{|l|}{ Dimensão Transparência Ativa } \\
\hline Entraves & Propost \\
\hline $\begin{array}{l}\text { - Falta de destaque para os instrumentos de } \\
\text { planejamento e orçamento } \\
\text { - Falta de resumo didático dos instrumentos de } \\
\text { planejamento o orçamento } \\
\text { - Informações sobre liquidação e pagamento de } \\
\text { despesas pouco detalhadas } \\
\text { - Informação com despesas com servidores incompleta } \\
\text { - Informação sobre beneficiários de pagamentos } \\
\text { incompleta } \\
\text { - Informações desatualizadas sobre Convênios } \\
\text { - Informações sobre Receitas Públicas pouco detalhadas } \\
\text { - Informações sobre Receitas Públicas não tempestivas } \\
\text { - Patrimônio público sem valores individualizados e sem } \\
\text { depreciação contabilizada } \\
\text { - Relatórios de Controle Interno não tempestivos }\end{array}$ & $\begin{array}{l}\text { - Disponibilizar em destaque na homepage os instrumentos de } \\
\text { planejamento e orçamento } \\
\text { - Disponibilizar peça didática e explicativa sobre os instrumentos de } \\
\text { planejamento e orçamento } \\
\text { - Detalhar e disponibilizar as informações sobre liquidação e } \\
\text { pagamento de despesas } \\
\text { - Detalhar e disponibilizar as informações sobre os servidores } \\
\text { - Detalhar e disponibilizar as informações sobre os beneficiários de } \\
\text { pagamentos } \\
\text { - Atualizar e disponibilizar as informações sobre convênios } \\
\text { - Detalhar, atualizar e disponibilizar as informações sobre as } \\
\text { receitas públicas } \\
\text { - Disponibilizar informações sobre o patrimônio com valores } \\
\text { individualizados e com depreciação acumulada contabilizada } \\
\text { - Atualizar e disponibilizar os relatórios de controle interno }\end{array}$ \\
\hline \multicolumn{2}{|l|}{ Dimensão Usabilidade e Funcionalidade } \\
\hline Entraves & Propc \\
\hline $\begin{array}{l}\text { - Falhas nas ferramentas de busca } \\
\text { - Falta de instrução para interação } \\
\text { - Falta de diferenciação entre links visitados e não } \\
\text { visitados } \\
\text { - Falta de incentivo para a criação de espaço para debate } \\
\text { entre os usuários e o poder público }\end{array}$ & $\begin{array}{l}\text { - Corrigir erros nas ferramentas de busca } \\
\text { - Redigir instruções para que ocorra interação dos usuários } \\
\text { - Diferenciar links visitados e não visitados } \\
\text { - Incentivar a criação de espaço para debate entre os usuários e o } \\
\text { poder público }\end{array}$ \\
\hline \multicolumn{2}{|l|}{ Dimensão Transparência Passiva } \\
\hline Entraves & le intervenção \\
\hline $\begin{array}{l}\text { - Nem sempre os pedidos são atendidos respondendo } \\
\text { ao que se perguntou }\end{array}$ & $\begin{array}{l}\text { - Aperfeiçoar o canal de comunicação, respondendo com clareza o } \\
\text { pedido do cidadão }\end{array}$ \\
\hline $\begin{array}{l}\text { - Nem sempre o ente federado comunica ao cidadão a } \\
\text { possibilidade de recurso }\end{array}$ & $\begin{array}{l}\text { - Aperfeiçoar o atendimento, informando o cidadão sobre a } \\
\text { possibilidade de recurso }\end{array}$ \\
\hline
\end{tabular}

A classificação obtida recomenda, portanto, em médio nível o portal como instrumento eletrônico público que possibilita ao cidadão o livre exercício do controle sobre os atos de seus governantes e uma participação no processo decisório de um maior número de pessoas e de qualidade argumentativa. Resta aos gestores públicos aprimorarem os pontos que dificultam a transparência. Dessa forma, no Quadro 12 serão apresentados os entraves percebidos e as propostas de intervenção para portal.

As intervenções tiveram a finalidade de oferecer ao portal eletrônico maior transparência da gestão dos recursos públicos. Como já foi dito, a transparência não tem finalidade em si, mas possibilita por parte da Administração Pública, accountability e o exercício democrático participativo-deliberativo. Os entraves observados podem comprometer a accountability e o exercício democrático participativo-deliberativo, pois o portal deveria alcançar o maior número de pessoas possível e focar na qualidade das informações 
oferecidas aos cidadãos. Além disso, os portais eletrônicos devem ser sempre confiáveis, claros e didáticos para os usuários.

O portal Goiás Transparente nem sempre se apresenta confiável, pois contém algumas informações desatualizadas e incompletas. Nem sempre traz clareza a todos os cidadãos em seus conteúdos orçamentários, dificultando compreensão dos usuários. Nem sempre é didático, pois traz relatórios às vezes extensos e cujo o acesso não é simplificado, mas se faz por vários passos e cliques. Suas ferramentas de busca nem sempre apontam para o mesmo conteúdo ou para o conteúdo adequado. Além disso, no portal falta incentivo ao controle social e falta a promoção de debates e fóruns entre usuários e também com o poder público.

Como o portal Goiás Transparente não incentiva a participação social e nem sempre oferece base confiável e acessível de informação, é pouco provável que ele possibilite a prestação de contas e o exercício democrático deliberativo de forma eficaz, visto que segundo Rocha (2011) aos governantes cabe a obrigação de prestar contas de suas ações e aos cidadãos, o papel de vigilância sobre os atos de seus governantes. Portanto, o portal Goiás Transparente não é um instrumento pleno de accountability e de democracia, já que sua função de controle social por vezes está prejudicada pela má execução de algumas evidenciações e falta de incentivo ao exercício democrático. Por isso, apesar de possuir um médio nível de transparência, o portal recebeu propostas de intervenção, para que de fato, possa ser ponto de partida para o exercício democrático.

\section{CONCLUSÕES}

Após a compilação dos resultados da pesquisa, concluiu-se que, apesar de o portal apresentar características funcionais de boa qualidade, ampla gama de informações e serviços, ele não contribui com plenitude para o exercício do controle social pelo cidadão, pois não há espaços de interação, falta incentivo à participação social e algumas informações não são prestadas de forma tempestiva o que dificulta o diálogo entre Poder Público e sociedade.

A pesquisa não é exaustiva na análise sobre democracia, accountability e transparência, mas ofereceu uma nova medida para avaliar aspectos relacionados à transparência ativa, transparência passiva, conteúdo e visão geral e usabilidade e funcionalidade. Novos elementos de análise devem surgir e podem ser incorporados à modelagem, aumentando a amplitude dos estudos. Além disso, o estudo limitou-se à análise do Portal de Transparência do Estado de Goiás com foco sobre a atuação do gestor público, não levando em consideração a eficiência da transparência das informações junto ao usuário do portal.

Como sugestão a outras pesquisas na mesma linha, pode-se incluir estudos sobre avaliação do papel do cidadão na accountability e no exercício democrático participativo-deliberativo. Pode-se aplicar a Modelagem TLS em outros portais de transparência e, ainda, desenvolver outras mensurações de transparência, de modo que tal aferição possa ser realizada de forma mais completa e ofereça, se bem executada, totais condições do lado da Aministração Pública de possibilitar o exercício da democracia participativa-deliberativa. 


\section{REFERÊNCIAS}

AKUTSU, L.; PINHO, J. A. G.. Sociedade da informação, accountability e democracia delegativa: investigação em portais de governo no Brasil. Revista de Administração Pública, Rio de Janeiro, v.5, p.723-745, 2009.

ANDRADE, M. D.; ARAGÃo NETO, L. A. P.. Por que é tão complicada a aplicação efetiva do processo de accountability no Brasil?. Revista Quaestio luris, v.12, n.1, 2019.

BIZERRA, A. L. V.. Governança no setor público: a aderência dos relatórios de gestão do Poder Executivo municipal aos princípios e padrões de boas práticas de governança. Dissertação (Mestrado em Ciências Contábeis) Universidade do Estado do Rio de Janeiro, Rio de Janeiro, 2011.

BOBBIO, N.. Teoria geral da política: a filosofia política e as lições dos clássicos. Rio de Janeiro: Campus, 2000.

BRASIL. Constituição Federal de 1988. Promulgada em 5 de outubro de 1988. Brasília: Planalto, 1988.

BRASIL. Lei Complementar no 101, de 4 de Maio de 2000. Brasília: Planalto, 2000.

BRASIL. Lei Complementar no 131, de 27 de Maio de 2009. Brasília: Planalto, 2009.

BRASIL. Decreto n.§ 7.185, de 27 de maio de 2010. Brasília: Planalto, 2010.

BRASIL. Lei № 12.527, de 18 de novembro de 2011. Brasília: Planalto, 2009.

MENEZES, D. M. O.; MESSIAS, G. G. M.. Democracia e representação: dilemas da participação no Brasil. 2019.

GIL, A. C.. Métodos e técnicas de pesquisa social. São Paulo: Atlas, 1999.

HABERMAS, J.. Direito e democracia: entre faticidade e validade. Rio de Janeiro: Tempo brasileiro, 1997.

HOSSER, C.; CRUZ, A. P. C.; MACHADO, D. G.; QUINTANA, A. C.. Portal da transparência: um estudo comparativo entre os municípios de porto alegre e pelotas. Contexto, Porto Alegre, v.15, n.30, p.94-110, 2016.

INESC. Instituto de Estudos Socioeconômicos. Transparência orçamentária nas Capitais do Brasil. Brasília: INESC, 2012.

LAGO, R. C. B.. Democracia e controle social: A denúncia ao Tribunal de Contas da Bahia como instrumento de accountability. Dissertação (Mestrado em Políticas Sociais e Cidadania) - Universidade Católica de Salvador, Salvador, 2008.

LEITE FILHO, G. A.; COLARES, A. F.V; ANDRADE, I. C. F.. Transparência da Gestão Fiscal Pública: um Estudo a Partir dos Portais Eletrônicos dos Maiores Municípios do Estado de Minas Gerais. Contabilidade Vista \& Revista, v.26, n.2, p.114-136, 2015.

LOCKE, J.. Coleção os pensadores. São Paulo: Abril, 1973.
MACHADO JÚNIOR, E. V.. Sinergia dos Stakeholders: Um Framework de gestão e Responsabilidade Social-Estudo de Caso em Instituição de Ensino Superior Brasileira. Tese de Doutorado, Universidade Metodista de Piracicaba, Piracicaba, 2009.

NOSSA, V.. Disclosure ambiental: uma análise do conteúdo dos relatórios ambientais de empresas do setor de papel e celulose em nível internacional. Tese (Doutorado em Controladoria e Contabilidade) - Universidade de São Paulo, São Paulo, 2002.

GAMA NETO, R. B.. Índice de transparência dos estados brasileiros e controle social: notas Introdutórias. Conexão Política, v.2, n.2, p.63-75, 2014.

NUNES, G. S. F.; SANTOS, V.; FARIAS, S. SOARES, S. V.; LUNKES, R. J.. Análise dos Instrumentos de Transparência contidos na Lei de Responsabilidade Fiscal nos Municípios da Região Sul. Revista Ambiente Contábil, v.5, n.2, p.128, 2013.

O'DONNELL, G.. Accountability horizontal e novas poliarquias. Lua Nova, São Paulo, n.44, p.27-52, 1998.

PINHO, J. A. G.; SACRAMENTO, A. R. S.. Accountability: já podemos traduzi-la para o português?. Revista de Administração Pública, v.43, n.6, p.1343-1368, 2009.

PISA, B. J.. Uma proposta para o desenvolvimento do índice de avaliação da governança pública (IGovP): instrumento de planejamento e desenvolvimento do estado. Dissertação (Mestrado em Planejamento e Governança Publica) Universidade Tecnológica Federal do Paraná, Curitiba, 2014.

PNUD. Programa das Nações Unidas para o Desenvolvimento. $\mathbf{O}$ que é o IDHM. Nova lorque: PNUD, 2016.

ROCHA, A. C.. Accountability na administração pública: modelos teóricos e abordagens. Contabilidade, Gestão e Governança, v.14, n.2, 2011.

ROTHBERG, D.; LIBERATO, F. P.. Comunicação pública, transparência e políticas públicas: avaliação de informações em portais brasileiros de governo. Revista Internacional de Relaciones Públicas, v.3, n.6, p.69-96, 2013.

ROUSSEAU, J.-J.. Discurso sobre a economia política e do contrato social. Petrópolis: Vozes, 1995.

SCHEDLER, A.. Conceptualizing accountability. In: SCHEDLER, A.; DIAMOND, L.; PLATTNER, M. F.. The self-restraing state. Power and accountability in new democracies. Boulder and London: Lynne Rienner Publishers, 1999.

SCHUMPETER, J. A.. Capitalismo, Socialismo e Democracia. Rio de Janeiro: Zahar, 1984.

VIANA, C. C.; TAME, C. M. V. S.; SOUZA, W. A. R.; LIMA, M. S.. Avaliação da aderência aos critérios internacionais de transparência para a divulgação e apresentação das contas públicas municipais. Revista Ambiente Contábil, Natal, v.5, n.1, p.152-178, 2013.

VILELLA, R. M.. Conteúdo, usabilidade e funcionalidade: três 
dimensões para a avaliação de portais estaduais de governo eletrônico na web. Dissertação (Mestrado em Ciência da Informação) - Universidade Federal de Minas Gerais, Belo Horizonte, 2003.

YIN, R. K.. Estudo de Caso: planejamento e métodos. Porto
Alegre: Bookman, 2001

ZUCCOLOTTO, R.; TEIXEIRA, M. A. C.; RICCIO, E. L.. Transparência: reposicionando o debate. Revista Contemporânea de Contabilidade, v.12, n.25, p.137-158, 2015.

A CBPC - Companhia Brasileira de Produção Científica (CNPJ: 11.221.422/0001-03) detém os direitos materiais desta publicação. Os direitos referem-se à publicação do trabalho em qualquer parte do mundo, incluindo os direitos às renovações, expansões e disseminações da contribuição, bem como outros direitos subsidiários. Todos os trabalhos publicados eletronicamente poderão posteriormente ser publicados em coletâneas impressas sob coordenação da Sustenere Publishing, da Companhia Brasileira de Produção Científica e seus parceiros autorizados. Os (as) autores (as) preservam os direitos autorais, mas não têm permissão para a publicação da contribuição em outro meio, impresso ou digital, em português ou em tradução. 